\title{
Correction to: Leveraging Geospatial Approaches to Characterize the HIV Prevention and Treatment Needs of Out-of-School Adolescent Girls and Young Women in Ethiopia
}

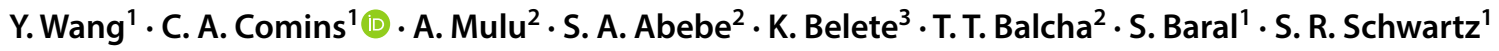

Published online: 22 September 2019

(c) The Author(s) 2019

\section{Correction to: AIDS and Behavior https://doi.org/10.1007/s10461-019-02537-1}

The article "Leveraging Geospatial Approaches to Characterize the HIV Prevention and Treatment Needs of Out-ofSchool Adolescent Girls and Young Women in Ethiopia" written by Y. Wang, C. A. Comins, A. Mulu, S. A. Abebe, K. Belete, T. T. Balcha, S. Baral, S. R. Schwartz, was originally published electronically on the publisher's internet portal (currently SpringerLink) on 27th May 2019 without open access.

With the author(s)' decision to opt for Open Choice the copyright of the article changed on 19th September 2019 to (C) The Author(s) 2019 and the article is forthwith distributed under the terms of the Creative Commons Attribution 4.0 International License (http://creativecommons.org/licenses/ by/4.0/), which permits use, duplication, adaptation, distribution and reproduction in any medium or format, as long as you give appropriate credit to the original author(s) and the source, provide a link to the Creative Commons license and indicate if changes were made.

The Original article has been corrected.

Publisher's Note Springer Nature remains neutral with regard to jurisdictional claims in published maps and institutional affiliations.

The original article can be found online at https://doi.org/10.1007/ s10461-019-02537-1.

C. A. Comins

ccomins1@jhu.edu

1 Department of Epidemiology, Johns Hopkins Bloomberg School of Public Health, 615 N Wolfe St E7003, Baltimore, MD 21231, USA

2 Armauer Hansen Research Institute (AHRI), Addis Ababa, Ethiopia

3 United States Agency for International Development, Addis Ababa, Ethiopia 